\title{
Las islas Galápagos: Tesoro natural
}

Oswaldo Báez Tobar - oswaldobaez@hotmail.com

Las islas Galápagos son reconocidas por la comunidad científica internacional como formaciones naturales únicas en el mundo y un hito importante en la historia de las ciencias biológicas por estar vinculadas a la teoría de la evolución desde su formulación original por Charles Darwin hasta la interpretación moderna. Son un museo y laboratorio de la evolución como se desprende del registro inigualable de investigaciones y publicaciones científicas.

Las Galápagos forman parte del patrimonio natural del Ecuador al integrar el Sistema Nacional de Áreas Protegidas desde 1959 cuando fueron declaradas Parque Nacional, al que se sumó Reserva Marina de Galápagos en 1998.

Por el extraordinario valor e importancia tanto el área terrestre como la reserva marina fueron incorporadas a la lista de Patrimonio Mundial, y además como Reserva de Biosfera. La reserva marina de Galápagos es la segunda más grande del mundo y está calificada como un tesoro natural de la humanidad.

El trabajo mancomunado del Servicio del Parque Nacional Galápagos bajo la administración del Ministerio del Ambiente, con la Fundación y la Estación Darwin constituye un ejemplo de acción concertada de instituciones ecuatorianas e internacionales para la investigación y conservación de los ecosistemas insulares. Sus resultados son reconocidos mundialmente como modelo de manejo y conservación. Empero, múltiples factores de orden económico, social, político y administrativo continúan incidiendo en los ecosistemas galapagueños y sus componentes más delicados que son sus especies endémicas.

La problemática de Galápagos es compleja debido a la fuerte inmigración hacia las Islas; al incremento desmedido de la actividad turística que origina mayor demanda de abastecimientos básicos (agua dulce, alimentos, combustibles, bienes y servicios), y a la vez que incrementa los residuos y contaminantes. Por otra parte la introducción de nuevas especies de plantas y animales, la fuerte presión sobre los recursos marinos por pescadores locales y del continente; la tendencia a la expansión del área urbana y agropecuaria a expensas de la superficie del Parque Nacional y de sus recursos provocan fuertes impactos en los sistemas ecológicos insulares y marinos.

Frente esto se impone la aplicación urgente de una nueva política de Estado para salvaguardar el patrimonio natural del Archipiélago, pues su conservación es responsabilidad ineludible del Estado ecuatoriano. Las Galápagos son un motivo de orgullo y también una alta responsabilidad; por ser una región excepcional requieren un tratamiento diferente al de cualquier región del Ecuador, como lo establece la nueva Constitución Política de la República. El Estado ecuatoriano está obligado a dar al Archipiélago un nuevo estatuto jurídico, que debe partir del cumplimiento de la norma constitucional y de la reforma a la Ley Especial para Galápagos, para hacer prevalecer el 
interés nacional por la conservación del archipiélago por sobre los intereses locales o sectoriales.

La conservación de Galápagos debe ser un componente prioritario en la política de ordenamiento y administración territorial del país; debe incluir el control en las áreas terrestres y marinas, una mayor eficiencia administrativa, regulación y control del turismo, limitación de las obras de infraestructura a lo estrictamente indispensable y con el mínimo impacto ambiental y el uso de energías limpias. El alto objetivo de conservación de las Galápagos exige acciones concertadas entre científicos y administradores, operadores de turismo y pescadores, comunidad residente en las Islas, representantes de las funciones del Estado y dirigentes políticos y la sociedad nacional; porque la conservación del Archipiélago es responsabilidad de todos.

El Ecuador asumió el reto de demostrar a la comunidad internacional que tiene la voluntad política y la capacidad técnicoadministrativa para desarrollar una gestión planificada y eficiente que asegure la conservación de las Galápagos, ejecutando acciones planificadas y coordinadas entre el Estado ecuatoriano, la Estación Charles Darwin y ONGs conservacionistas nacionales e internacionales. Los esfuerzos y logros en materia de conservación del Archipiélago son encomiables y son reconocidos por la comunidad internacional. Las Islas Galápagos representan la proyección de la soberanía ecuatoriana en el Pacífico y consolidan la presencia del Ecuador en el mundo entero.

\section{NOTAS}

- Extracto del Art. 258 de la Constitución: "La provincia de Galápagos tendrá un gobierno de régimen especial. Su planificación y desarrollo se organizará en función de un estricto apego a la conservación del patrimonio natural del Estado y del buen vivir, de conformidad con lo que la ley determine. Su administración estará cargo de un Consejo de Gobierno presidido por el representante del Presidente de la República... Dicho Consejo de Gobierno tendrá a su cargo la planificación y manejo de los recursos y organización de las actividades que se realicen en la provincia..."

- Creación del Parque Nacional Galápagos. Mediante Decreto Ley de Emergencia del 4 de julio de 1959 se declaran "parques nacionales de reserva de exclusivo dominio del Estado, para la conservación de la flora $\mathrm{y}$ fauna todas las tierras que forman las islas del Archipiélago de Colón o Galápagos..." Este año se cumplen 50 años del establecimiento del Parque Nacional Galápagos cuya administración está a cargo del Ministerio del Ambiente.

- La Fundación Charles Darwin para las Islas Galápagos se organizó en Europa el año 1959 con el auspicio de la UNESCO, UICN y por instituciones y científicos de todo el mundo, con el propósito de promover la investigación científica y la conservación de la flora y fauna insular. Este año la Fundación Charles Darwin cumple 50 años de fecundo trabajo por la conservación de Galápagos, que en la parte operativa se cumple a través de la Estación Científica del mismo nombre que se estableció la isla Santa Cruz, con el patrocinio del Gobierno ecuatoriano el año 1964. En la Estación laboran numerosos científicos y técnicos ecuatorianos y extranjeros para levantar la información científica básica y aplicada a la conservación de las Galápagos. 